\title{
Toward the origin of the conformational preference of 2-methoxyoxane, a model useful to study the anomeric effect
}

\section{Karina Martinez, ${ }^{\text {a }}$ Fernando Cortes, ${ }^{\text {a Ingrid Leal, }}{ }^{\text {b }}$ Vanessa Reyna, ${ }^{\text {b Delia Quintana, }}$ Sandra Antúnez, ${ }^{\mathrm{d}}$ and Gabriel Cuevas ${ }^{*}$ a}

a Instituto de Química, Universidad Nacional Autónoma de México, Circuito Exterior, Ciudad Universitaria, Coyoacán 04510, México, D.F., México. ${ }^{b}$ Escuela de Ciencias Químicas, Universidad La Salle, Benjamín Franklin 47, Hipódromo Condesa, 06140 México, D.F., México

${ }^{c}$ Centro de Investigación en Ciencia Aplicada y Tecnología avanzada. Instituto Politécnico Nacional. Unidad Legaria. Av. Legaria 694. Col. Irrigación 01500, México, D.F. México

${ }^{d}$ College of San Mateo, 1700 W. Hillsdale Blvd., San Mateo, CA 94402, USA E-mail: gecgb@servidor.unam.mx

(received 17 Aug 03; accepted 03 Dec 03; published on the web 09 Dec 03)

\begin{abstract}
The potential energy curves resulting from the $\mathrm{C}_{2}-\mathrm{O}_{\text {exo }}$ bond rotation of 2-OMeOxane were calculated. One minimum was found for the axial conformer at MP2/6-31G(d,p); B3LYP/6$31 \mathrm{G}(\mathrm{d}, \mathrm{p})$; and HF/6-31G(d,p) levels, and two minima in the equatorial conformer. The difference in the entropy of mixing between both conformers has a positive value, close to zero, which means that the entropy is higher for the equatorial conformer. The Scheme of rotation of the methoxy group at position 2 of oxane with six conformers, usually employed to describe this conformational process, is inadequate.
\end{abstract}

Keywords: Anomeric effect, conformational analysis, 2-methoxyoxane

\section{Introduction}

Carbohydrates are widely distributed in Nature and are very important compounds for biological functions of living organisms. ${ }^{1}$ Because physicochemical properties of molecules depend on their conformations or arrangements their atoms adopt in space, ${ }^{2}$ it is fundamental to understand what are the principles that control these conformational preferences. Amongst the conformational phenomena involved in the control of the molecular arrangements observed in carbohydrates, the anomeric $^{3}$ and the gauche effects ${ }^{4}$ are the most prominent.

The term anomeric effect was introduced in 1958 by Lemieux ${ }^{5}$ and refers to the tendency of an electronegative substituent at $\mathrm{C}_{2}$ of a pyranoid ring (see Scheme 1) to adopt the axial rather than the equatorial orientation, in contrast with expectations based exclusively on steric 
considerations. The phenomenon is not restricted to carbohydrates, and the anomeric effect was subsequently studied in simpler analogues for isolation from other conformational effects such as tetrahydopyran derivatives where the 2-methoxy derivative has been widely studied.

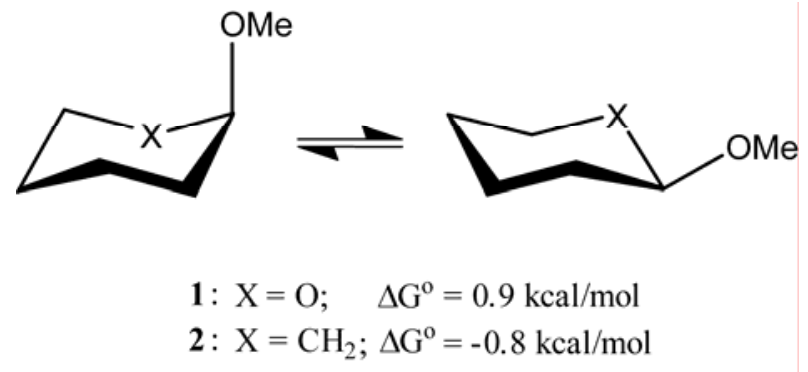

\section{Scheme 1}

Computational limitations led first to the use of dimethoxymethane as a simplified model of the anomeric segment $\mathrm{O}-\mathrm{C}-\mathrm{O} .{ }^{7}$ but with stronger computational power, models such as 2methoxyoxane (2-OMe-oxane or 2-methoxytetrahydropyran, 2-OMe-THP 1, Scheme 1), where computational and experimental results can be directly compared, more thorough computational methods can be applied in reasonable time. The conformational preference of 2-MeO-oxane is a good model for the study of the anomeric effect, because it not only allows its isolation from other conformational effects, but also is easy to synthesize, and to analyze by both, spectroscopic ${ }^{6}$ and computational methods. ${ }^{8-10}$

Recently, the study of the contributions of the electronic delocalization to the anomeric effect showed that the observed axial/equatorial conformational preference is not solely of stereoelectronic origin ${ }^{11}$ since the stereoelectronic interactions present in the axial conformer are as important as the ones in the equatorial arrangement.

The anomeric effect in 2-MeO-oxane was found to be $1.7 \mathrm{kcal} / \mathrm{mol}$, from the difference of $\Delta G^{\circ}$ for the axial/equatorial equilibrium of $1,0.9 \mathrm{kcal} / \mathrm{mol}$, and the A Value for the methoxy group, $-0.8 \mathrm{kcal} / \mathrm{mol}(2$, Scheme 1$)$.

Experimental data support the view that the axial preference of the methoxy group in oxane is a result of entropic effects as opposed to the one where the free conformational energy would be driven by the enthalpic term of the equation, itself a function of steric, electrostatic, or stereoelectronic effects. Booth et al. ${ }^{12}$, for instance, studied the conformational equilibrium for 2OMe-THP (1) in the temperature range of 143 and $165 \mathrm{~K}$, and found $\Delta H^{\circ} \approx 0.0 \mathrm{kcal} / \mathrm{mol}$ and $\Delta S^{\circ}$ $=-2.7$ ue. Also, the equilibrium of a mixture of the conformationally homogeneous cis- and trans-2-methoxy-4-methyltetrahydropyran in the presence of 4-methylbenzenesulphonic acid at $273 \mathrm{~K}$ and $245 \mathrm{~K}$ gave a cis/trans ratio of 0.268 .

In order to account for the increased entropy in the axial isomer, Booth assumed that the populations of both rotamers ax-3 and eq-3 are negligible (Scheme 2), and that the population of the less stable rotamer ax-1 (in ax-1 $\rightleftharpoons$ ax-2) is much greater than the population of the less stable rotamer eq-1 (in eq-1 $\rightleftharpoons$ eq-2). However, in Booth's words "the unusually high 
conformational entropy difference cannot be reconciled with the entropy of mixing, calculated on the basis of only two rotamers for each conformation, and suggests that the individual rotamers may have appreciably different entropies."
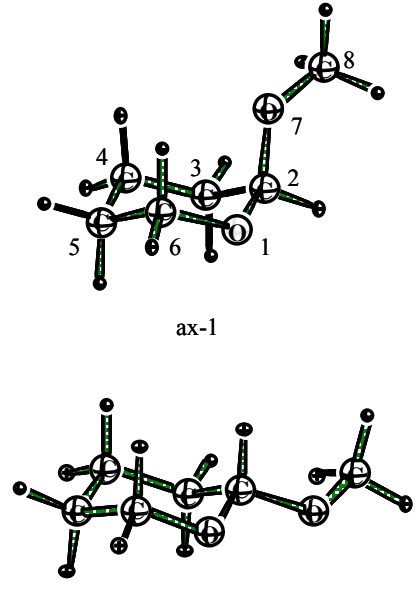

eq-1

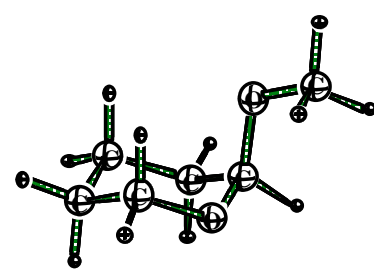

ax-2

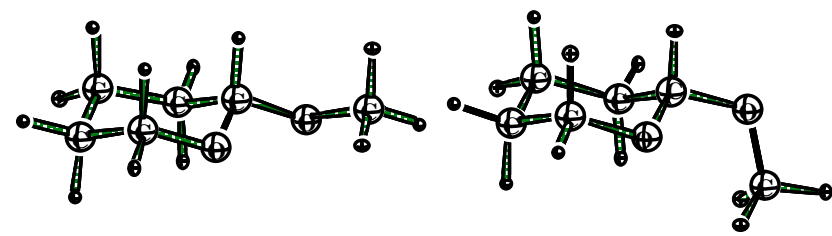

eq-2

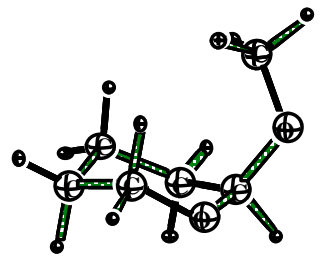

ax-3

eq-3

Scheme 2. Expected rotamers of 2-methoxytetrahydropyran.

The conclusion that there is a dominant change in entropy with a small change in enthalpy, has been questioned by Lemieux ${ }^{1}$, who suspected Booth's findings reflected specific solvation effects. The anomeric effect is indeed very sensitive to the solvent dielectric constant. ${ }^{13}$ It has been observed that the axial conformational preference is increased in polar solvents under a variety of experimental conditions.

Praly and Lemieux determined the solvent effect on the thermodynamic equilibria for 2-MeTHP and found $\Delta H^{\circ}$ close to zero only in polar or hydrogen bonding solvents. In contrast, in $\mathrm{CCl}_{4}$ containing mixtures, the enthalpy term was found in the range of $\Delta H^{\mathrm{o}}=0.6$ to 0.8 $\mathrm{kcal} / \mathrm{mol}^{1}$

A calorimetric study of 4,6-dimethyl-2-methoxytetrahydropyran allowed to establish a value of $\Delta H^{\mathrm{o}}=1.21 \pm 0.07 \mathrm{kcal} / \mathrm{mol}$ in gas phase. ${ }^{14}$ This value has been satisfactorily reproduced by theoretical methods incorporating electronic correlation.

The decreased entropy in the equatorial conformer was explained by Lemieux ${ }^{1}$ in terms of a release of solvent when the equatorial conformer passes into the axial form. Solvent molecules would "trap" the equatorial conformer, losing degrees of freedom that are regained when passing to the axial arrangement. Indeed, since the endo-cyclic oxygen in the equatorial isomer is not engaged in any stereoelectronic effect it should be especially electron rich and prone to solvation.

The main goals of this paper is to determine the real participation of conformers shown in Scheme 2 in the conformational equilibrium of $\mathbf{1}$ by the evaluation of the energy potential and population curves around the $\mathrm{C}-\mathrm{OMe}$ rotation, to contrast Booth's conclusion and to get the best 
description possible of the gas phase potential energy, which is a necessary preliminary step to a full description of the ensemble in solution (either using a continuum model or a molecular dynamics treatment, based on, e.g. a change of parameters using the highly accurate properties obtained here). Likewise, that these gas phase results should not be directly compared with experimental data obtained in solution.

\section{Results and Discussion}

\section{A. Energetic considerations}

Complete geometry optimizations (without symmetry constraints) of axial and equatorial conformers of minimum energy (with no imaginary frequencies) were carried out at MP2/6$31 \mathrm{G}(d, p)$ and within the frame of DFT at B3LYP/6-31G $(d, p)$ level with Gaussian 94 program (G94). ${ }^{15}$ In all cases, low energy isomers have a chair conformation.

Additionally, rotation of the methoxy group was carried out and energy and population curves were obtained with uniform scanning at $10^{\circ}$ increments for dihedral angles $\mathrm{O}_{1}-\mathrm{C}_{2}-\mathrm{O}_{7}-\mathrm{C}_{8}$ (see numbering system in Scheme 2) in both axial and equatorial 2-MeO-oxane, allowing for complete relaxation of the rest of the atomic coordinates. Each point of the population curves, $\mathrm{P}_{i}$, corresponds to the Boltzmann probability of the ith conformational state, according to equation 1.22

$$
P=\frac{e^{-E_{i} / R T}}{\sum_{i=1}^{n} e^{-E_{i} / R T}}
$$

Table 1 shows the energy results at MP2 and HF/3-21G levels of theory for each relevant conformational arrangement. Table 2 shows the B3LYP/6-31G $(d, p)$ energy calculations. All conformers are minima with no imaginary frequencies. It is worth noticing at this point that in Salzner and Schleyer's paper, ${ }^{9}$ only four minima, conformers ax-1, ax-2, eq-2, and eq-3, of the six expected for the rotation of the methoxy group were described excluding from their calculations, at HF/6-31G(d) level, conformers ax-3 and eq-1. On the other hand, in the absence of symmetry in $\mathbf{1}$, and with evident computational limitations, Wiberg et al. ${ }^{10}$ considered that at $\mathrm{HF} / 3-21 \mathrm{G}$ level it was acceptable to take into account only one minimum energy conformer for the axial configuration, ax-2, and two for the equatorial configuration, eq- 2 and eq- 3 .

Our results show that, for all methods, the most stable conformer in terms of total energy, is ax-2 (Tables 1 and 2), followed by rotamer eq-2, only 1.2 to $2.5 \mathrm{kcal} / \mathrm{mol}$ above ax- 2 . Although ax-1 is of lower energy than eq-3, the former does not represent a minimum, as eq-3 does. It is lying in a well defined well from which it requires to pass energy barriers of $\sim 2.5$ and $\sim 5$ $\mathrm{kcal} / \mathrm{mol}$ to become either the most stable 2-eq, and the least stable eq-1, respectively (Scheme 3). 
Table 1. Energy terms of relevant conformers of 2-OMeTHP of lower energy at MP2/6-31G $(d, p)$ and HF level of theory at $298 \mathrm{~K}^{\mathrm{a}}$

\begin{tabular}{|c|c|c|c|c|c|c|}
\hline & $a x-1$ & $a x-2$ & $a x-3$ & $e q-1$ & $e q-2$ & $e q-3$ \\
\hline Total Energy (MP2) ${ }^{\mathrm{a}}$ & -385.13328 & -385.14045 & -385.12405 & -385.12943 & -385.13685 & -385.13251 \\
\hline Total Energy (HF) a & -383.91916 & -383.92542 & -383.90857 & -383.91615 & -383.92350 & -383.91874 \\
\hline Enthalpy ${ }^{\mathrm{a}}$ & -384.94007 & -384.94712 & -384.93065 & -384.93666 & -384.94390 & -384.93943 \\
\hline Entropy $b$ & 87.527 & 85.926 & 86.088 & 87.91 & 86.176 & 86.544 \\
\hline Free Energy ${ }^{a}, d$ & -384.98166 & -384.98795 & -384.97155 & -384.97843 & -384.98484 & -384.98055 \\
\hline $\mathrm{ZPCa}$ & 0.18438 & 0.18459 & 0.18469 & 0.18385 & 0.18417 & 0.18427 \\
\hline Total Energy + ZPC & -385.31766 & -385.32504 & -385.30874 & -385.31328 & -385.32102 & -385.31678 \\
\hline Rel(Total) at MP2 c & 4.50 & 0.0 & 10.29 & 6.92 & 2.26 & 4.98 \\
\hline $\operatorname{Rel}($ Correct.) MP2 c & 4.63 & 0.0 & 10.23 & 7.38 & 2.52 & 5.18 \\
\hline Rel(Total) $)^{c}$ at HF $c$ & 3.93 & 0.0 & 10.57 & 5.82 & 1.20 & 4.19 \\
\hline Rel(Enthalpy) ${ }^{\mathrm{c}}$ & 4.42 & 0.0 & 10.34 & 6.56 & 2.02 & 4.83 \\
\hline $\operatorname{Rel}(\text { Entropy })^{\mathrm{c}}$ & 1.60 & 0.0 & 0.16 & 1.98 & 0.25 & 0.62 \\
\hline Rel(Free Energy) ${ }^{\mathrm{c}, \mathrm{d}}$ & 3.95 & 0.0 & 10.29 & 5.97 & 1.95 & 4.64 \\
\hline
\end{tabular}

${ }^{\mathrm{a}}$ In hartrees. ${ }^{\mathrm{b}}$ In eu (cal/ $\left./ \mathrm{Kmol}\right) .{ }^{\mathrm{c}}$ In $\mathrm{kcal} / \mathrm{mol} .{ }^{\mathrm{d}}$ At $298 \mathrm{~K}$.

In Scheme 3, we compare axial and equatorial energies, subtracting rotamer ax-2's energy, the absolute minimum. At the three levels of theory studied here, conformer eq-3 is more stable than eq-1 in disagreement with Booth's ${ }^{12}$ original statement that discounted eq-3, based in steric considerations, as a participant in the rotameric population, but in agreement with Fuchs, ${ }^{19}$ who described that conformers analogous to eq- 2 are three times more abundant than those analogous to eq-3.

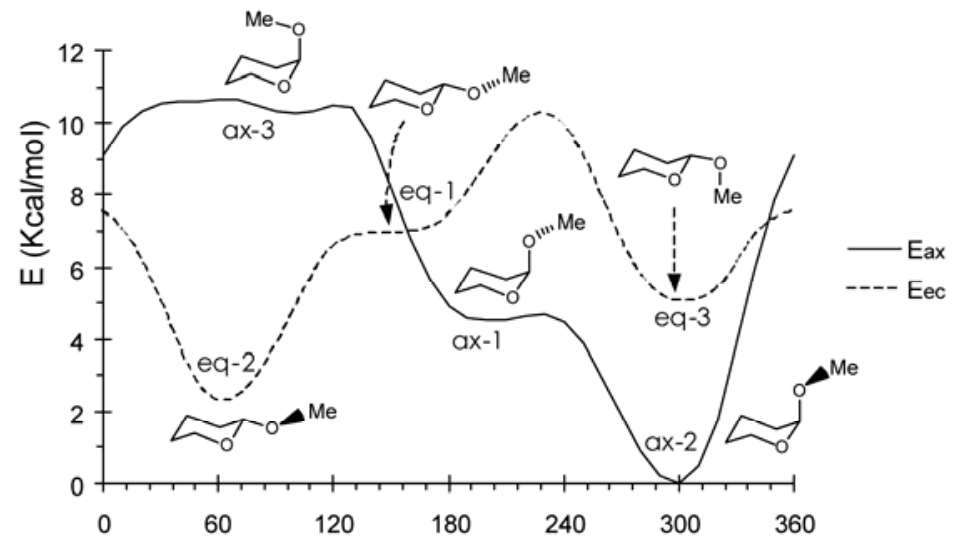

Scheme 3. Energy profiles for axial and equatorial 2-OMeTHP as calculated with MP2/6-31G $(d, p)$. 
Schemes 4 and 5 show the effect of the $\mathrm{O}_{1}-\mathrm{C}_{2}-\mathrm{O}_{7}-\mathrm{C}_{8}$ torsion angle rotation on the energy (solid lines) and population (dashed lines) of the axial and equatorial conformers, respectively. All levels of theory evaluated show the same tendencies with no significant difference in energy trends, both in the minima positions and the heights of the rotational barriers.

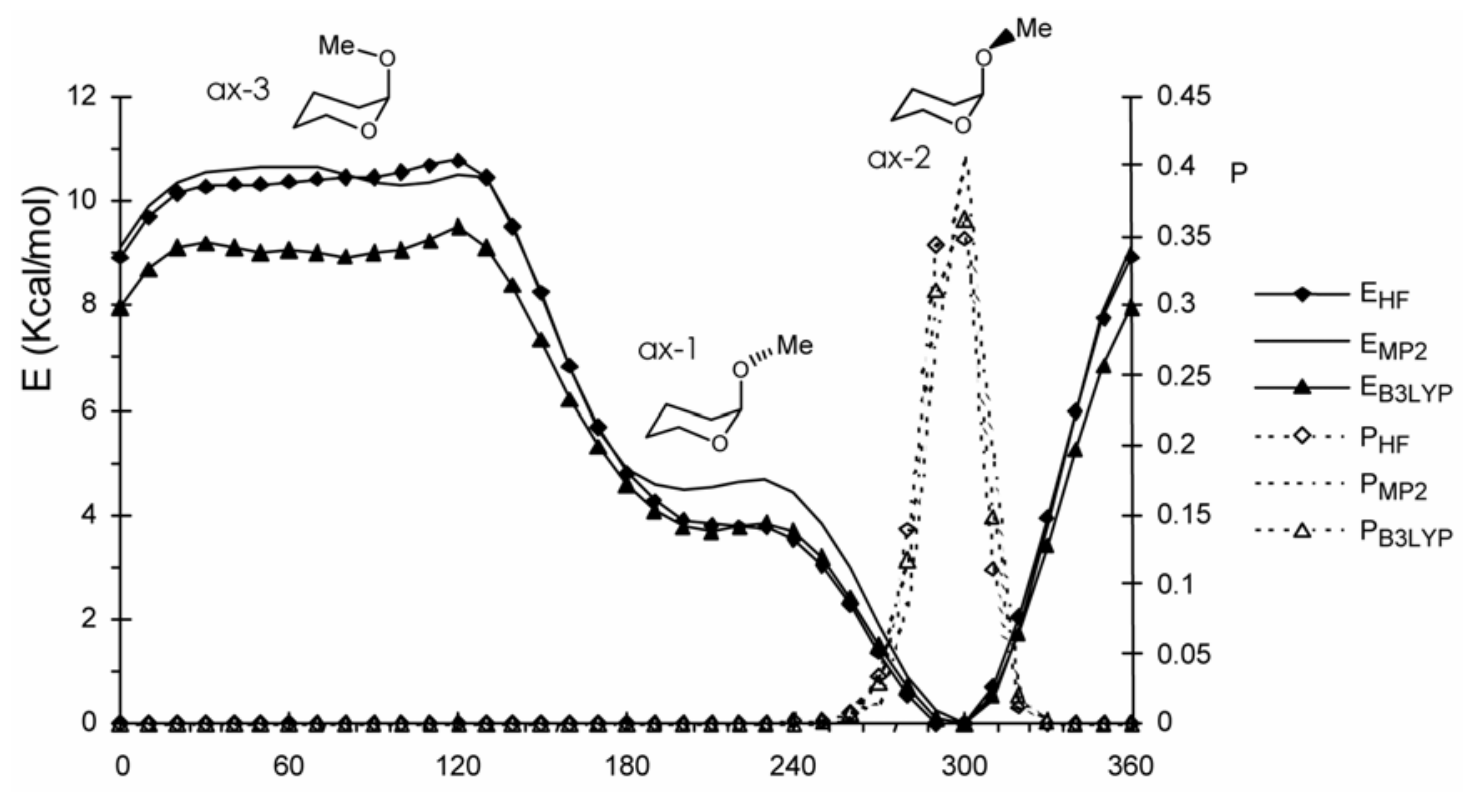

Scheme 4. Energy (E) and population (P) profiles for axial 2-OMeTHP at MP2/6-31G(d,p), $\mathrm{B} 3 \mathrm{LYP} / 6-31 \mathrm{G}(d, p)$, and HF level of theory.

The axial energy profiles (Scheme 4 ) show a steep well around $300^{\circ}$, corresponding to ax-2; a quasi minimum well, not quite defined, at $210^{\circ}$, ax-1; and a high energy plateau, ranging from around $0^{\circ}$ to $140^{\circ}$, rotamer ax-3, corresponding to the methyl group pointing inside any part of the THF ring. All rotamers along this energy plateau, in agreement with Booth's expectations, are not populated. The corresponding population curves reflect the energy curves, showing only one populated conformer contributing to the axial conformation, the minimum energy conformer ax-2. In this rotamer, the methyl group points toward the intramolecular oxygen, thereby preventing destabilizing steric interactions with the ring. In disagreement with Booth, ${ }^{12}$ we find that conformer ax-1 is not populated.

In Scheme 5, the equatorial energy curves show two well defined minima, at $60^{\circ}$, the lowest energy minimum, corresponding to eq- 2 ; and at $300^{\circ}$, almost $3 \mathrm{kcal} / \mathrm{mol}$ above, eq- 3 . While both rotamers contribute to the equatorial conformation, eq- 2 is largely dominant. Conformer eq- 1 , with the methyl group pointing inside the ring, does not represent a real minimum and neither does it contribute to the equatorial conformation. The relative energies studied here agree with the experimental observations of Fuchs, et al. ${ }^{19}$ 


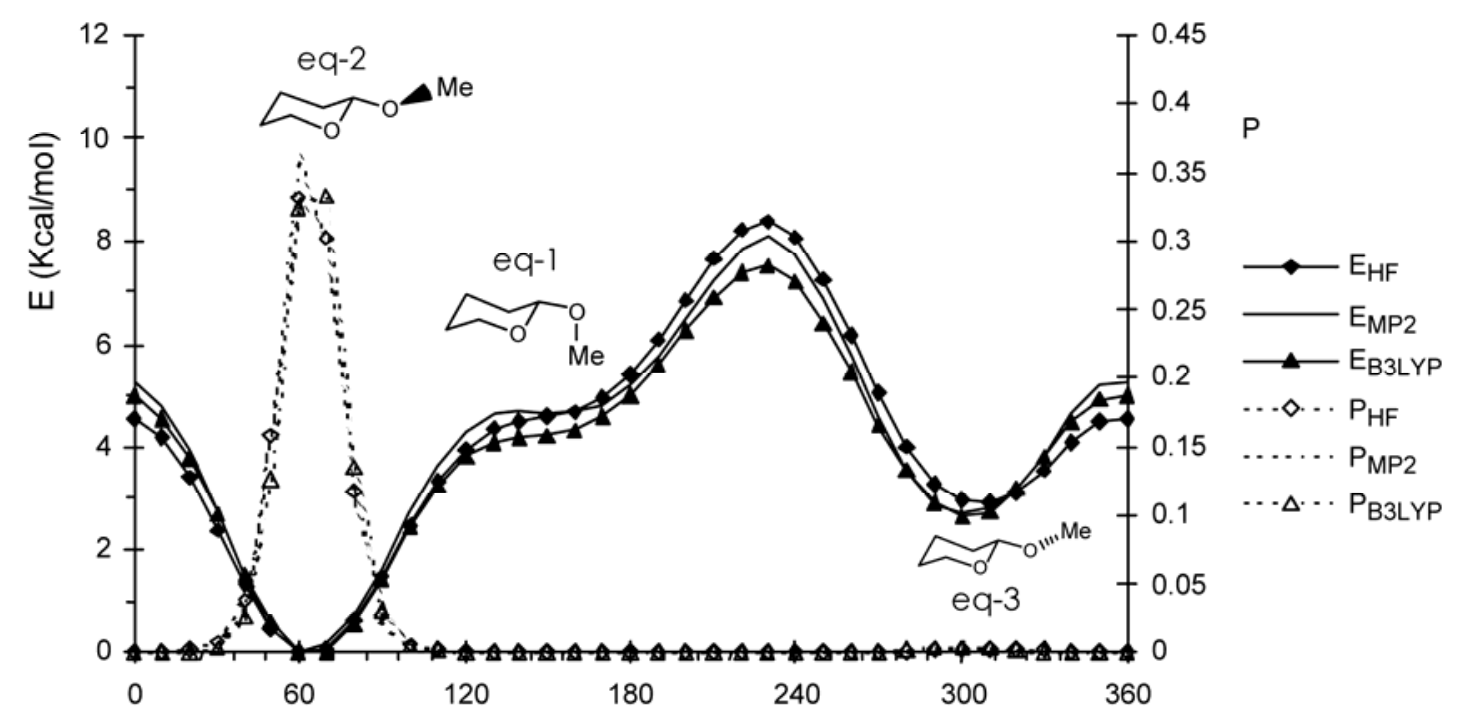

Scheme 5. Energy (E) and population (P) profiles for equatorial 2-OMeTHP at MP2/6-31G(d,p), B3LYP/6-31G(d,p), and HF level of theory.

From the statistical study of experimental data using X-ray-diffraction in 111 compounds including the anomeric segment of our interest, they concluded that the axial conformers are twice more common than the equatorial ones; that conformers with an arrangement similar to ax1 , eq-1 and ax-3 do not exist; that arrangements equivalent to eq- 2 and eq-3 show a distribution of $3: 1$. These facts are congruent with our results of relative energy minima and with those previously described. ${ }^{9,10}$ In a second contribution, Fuchs et al. ${ }^{20}$ studied 259 compounds containing the $\mathrm{O}-\mathrm{C}-\mathrm{O}$ moiety, which led them to conclude that conformers with an arrangement like eq-3 do not contribute to the rotational population, this time in agreement with our population results.

Table 2 displays the energies of the hypothetical Lewis molecules. The $\mathrm{E}_{\mathrm{Lew}}$ corresponds to the hypothetical molecule where hyperconjugation is absent. All conformers are minima with no imaginary frequencies. This energy is obtained by zeroing all orbital interactions by deletion of all off-diagonal elements of the density matrix, and leaving then only interactions of steric and polar nature to dictate the molecule's behavior. This information should assist in evaluating the contribution of electronic delocalization to the conformational preferences. ${ }^{11}$

At B3PLY/6-31G (d,p), in absence of electronic delocalization, our calculations predict that ax-2 is still the most stable conformer. If only steric effects are taken into account, the equatorial conformer should predominate, as has been shown by way of the delocalization energy contribution to the anomeric effect in similar segments. ${ }^{11}$ Although the absolute energy values are different from the ones obtained including electronic delocalization, the tendencies remain the same, with ax-3 still being the highest rotamer in energy, due, of course to the high steric repulsions found between the OMe and the ring. This might be just another case showing the weakness in this analysis of population, due to its high sensibility as a calculation tool. 
Table 2. Energy terms of lower energy conformers of 2-OMeTHP at B3LYP/6-31G(d,p) level, at $298 \mathrm{~K}^{\mathrm{a}}$

\begin{tabular}{|c|c|c|c|c|c|}
\hline & $a x-1$ & $a x-2$ & $a x-3$ & $e q-2$ & $e q-3$ \\
\hline Total Energya & -386.31002 & -386.31607 & -386.30172 & -386.31414 & -386.30989 \\
\hline Lewis Energy ${ }^{a}$ & -385.63062 & -385.63456 & -385.60059 & -385.62818 & -385.62747 \\
\hline Enthalpya & -386.12173 & -386.12759 & -356.11330 & -386.12701 & -386.12163 \\
\hline Entropy $b$ & 87.54 & 86.72 & 88.62 & 86.86 & 87.31 \\
\hline Free Energya,d & -386.16333 & -386.16879 & -386.15540 & -386.16733 & -386.16311 \\
\hline $\mathrm{ZPC}$ & 0.17932 & 0.17957 & 0.17941 & 0.17913 & 0.17928 \\
\hline Total + ZPC & -386.48934 & -386.49564 & -386.48113 & -386.49327 & -386.48917 \\
\hline $\operatorname{Rel}\left(\right.$ Total) ${ }^{\mathrm{c}}$ & 3.80 & 0.0 & 9.00 & 1.21 & 3.88 \\
\hline Rel (Correct.) & 3.95 & 0.0 & 9.11 & 1.49 & 4.06 \\
\hline $\operatorname{Rel}$ (Lewis) $^{\mathrm{c}}$ & 2.47 & 0.0 & 21.3 & 4.00 & 4.45 \\
\hline Rel (Enthalpy) ${ }^{\mathrm{c}}$ & 3.68 & 0.0 & 8.97 & 0.36 & 3.74 \\
\hline Rel (Entropy) ${ }^{\mathrm{c}}$ & 0.82 & 0.0 & 1.9 & 0.14 & 0.59 \\
\hline Rel (Free energy) $\mathrm{c}, \mathrm{d}$ & 3.43 & 0.0 & 8.40 & 0.92 & 3.56 \\
\hline
\end{tabular}

${ }^{\mathrm{a}}$ In hartrees. ${ }^{\mathrm{b}}$ In eu (cal/Kmol). ${ }^{\mathrm{c}}$ In kcal $/ \mathrm{mol} .{ }^{\mathrm{d}}$ At $298 \mathrm{~K}$.

\section{B. Geometrical considerations}

The anomeric effect of stereoelectronic origin can be measured by energy and/or by molecular geometry. In an endo hyperconjugative interaction the antiperiplanar arrangement of the $\mathrm{n}_{\mathrm{O}_{1}}-\mathrm{O}_{1^{-}}$$\mathrm{C}_{2}-\mathrm{O}_{7}$ moiety allows the transfer of $\mathrm{O}_{n}$ electrons to the $\sigma^{*}$ orbital, thus lengthening the $\mathrm{C}_{2}-\mathrm{O}_{7}$ bond; shortening the $\mathrm{O}_{2}-\mathrm{C}_{2}$ bond length; and increasing the $\mathrm{O}_{2}-\mathrm{C}_{2}-\mathrm{O}_{7}$ angle (Figure 1). On the other hand, an exo hyperconjugative interaction should result in a lengthening of the $\mathrm{O}_{\text {endo }}-\mathrm{C}_{2}$ bond, and a contraction of the $\mathrm{C}_{2}-\mathrm{O}_{\text {exo }}$ bond, by increasing its double bond character (Figure 1).
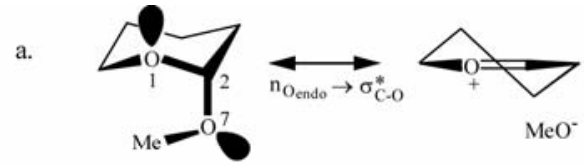

b.

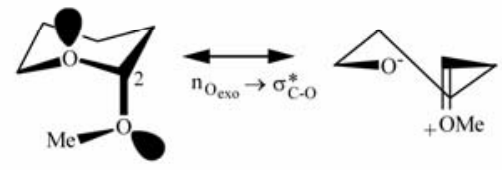

Figure 1. Double bond-no bond hybrid of (a) endo-anomeric stereoelectronic interaction, and of (b) exo-anomeric interaction. 
Figure 2 shows endo and exo-anomeric stereoelectronic interactions that could, at least $a$ priori, be active in rotamers of 2-OMeTHP. In this molecule all axial conformers allow for endoanomeric interactions, $n_{\mathrm{O}_{\text {endo }}} \rightarrow \sigma_{\mathrm{C}-\mathrm{O}}^{*}$, no matter what value the torsional angle takes, due to the fixed nature of the $\mathrm{O}-\mathrm{C}-\mathrm{O}$ fragment. The exo-anomeric interaction, instead, requires the torsional angle $\mathrm{O}_{1}-\mathrm{C}_{2}-\mathrm{O}_{7}-\mathrm{C}_{8}$ to adopt a value of either 60 or $180^{\circ}$ in order for the stereoelectronic interaction to take place. In the case of the axial arrangements only ax-2 and ax-3 would allow for this kind of interaction. By analyzing the geometrical data generated by the different methods studied in this paper it should be possible to assess the participation of these interactions in the conformational equilibria of 2-OMeTHP. In particular, bond distances $\mathrm{O}_{1}-\mathrm{C}_{2}$ and $\mathrm{C}_{2}-\mathrm{O}_{7}$, and $\mathrm{O}_{1}$ $\mathrm{C}_{2}-\mathrm{O}_{7}-\mathrm{C}_{8}$ torsion angle should shed some light into whether any exo or an endo anomeric interaction is taking place in a rotamer.

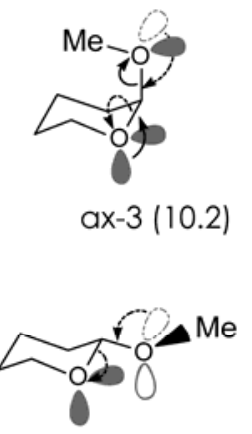

eq-2 (2.5)
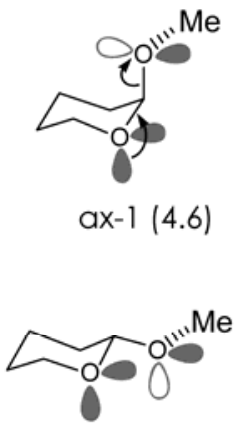

eq-1 (7.4)
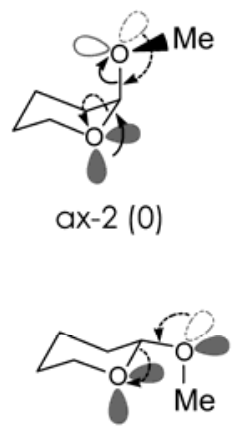

eq-3 (5.2)

Figure 2. Endo-anomeric $(\longrightarrow)$ and exo-anomeric $(--\rightarrow)$ stereoelectronic interactions. In parenthesis, the corrected total energy in $\mathrm{kcal} / \mathrm{mol}$ calculated by MP2 after subtracting $\mathrm{E}_{\mathrm{ax}-2}$ from each $\mathrm{E}$ value.

The only rotamer that shows neither endo nor exo anomeric interaction is eq-1, which is not a particularly high energy conformer, thus an adequate model to compare bond distance. Relevant geometric data at MP2 and B3LYP levels are in Table 3 and 4.

Compared with eq-1 bond distance values, ax-1 shows a shortened $\mathrm{O}_{1}-\mathrm{C}_{2}$ and a larger $\mathrm{C}_{2}-\mathrm{O}_{7}$ bond distance, in agreement with an endo interaction. It does not need a specific alignment, so it does not matter that the torsion angle is deviated more than $20^{\circ}$ from its ideal value for the interaction to occur. Ax-2, which could bear both endo and endo interactions, shows a slight increase in both bond distances. Torsion angle $\mathrm{O}_{1}-\mathrm{C}_{2}-\mathrm{O}_{7}-\mathrm{C}_{8}$ is practically not deviated from its ideal value, so we could expect an exo anomeric interaction to be taking place although we cannot discount an endo anomeric interaction to be active in this conformer. For conformer ax-3, which could in principle be experiencing both endo and exo interactions, we can discount the exo interaction since, the torsion angle is deviated $40^{\circ}$ from its ideal value. Bending angles $\mathrm{O}_{1}-\mathrm{C}_{2}-\mathrm{O}_{7}$ and $\mathrm{C}_{2}-\mathrm{O}_{7}-\mathrm{C}_{8}$ are pretty distorted too, overwhelmed by the strong steric interactions operating in 
this arrangement. Although we see an increase in bond distance $\mathrm{C}_{2}-\mathrm{O}_{7}$, in agreement with the endo interaction, it could just as well be an artifact from the great distorsion the molecule is subjected to.

Conformer eq- 2 shows geometrical values in accordance with the exo-anomeric interaction that in principle could be taking place, namely a shortened $\mathrm{C}_{1}-\mathrm{O}_{7}$ bond, an increased $\mathrm{O}_{2}-\mathrm{C}_{1}$ bond, and an almost perfect alignment of the torsion angle in question. The same holds true for rotamer eq-3 which can have only one stereoelectronic interaction, the endo-anomeric.

Table 3. Geometry of lower energy conformers of 2-OMeoxane at MP2/6-31G(d,p) level. ${ }^{a}$ (distances in $\AA$, angles in degrees)

\begin{tabular}{lllllll}
\hline & $a x-1$ & $a x-2$ & $a x-3$ & $e q-1$ & $e q-2$ & $e q-3$ \\
\hline $\mathrm{O}_{1}-\mathrm{C}_{2}$ & 1.403 & 1.419 & 1.418 & 1.412 & 1.426 & 1.426 \\
$\mathrm{C}_{2}-\mathrm{C}_{3}$ & 1.526 & 1.519 & 1.531 & 1.522 & 1.515 & 1.523 \\
$\mathrm{C}_{3}-\mathrm{C}_{4}$ & 1.526 & 1.527 & 1.531 & 1.529 & 1.530 & 1.529 \\
$\mathrm{C}_{4}-\mathrm{C}_{5}$ & 1.527 & 1.527 & 1.527 & 1.527 & 1.528 & 1.527 \\
$\mathrm{C}_{5}-\mathrm{C}_{6}$ & 1.520 & 1.519 & 1.519 & 1.521 & 1.521 & 1.521 \\
$\mathrm{C}_{6}-\mathrm{O}_{1}$ & 1.437 & 1.463 & 1.430 & 1.429 & 1.428 & 1.428 \\
$\mathrm{C}_{2}-\mathrm{O}_{7}$ & 1.424 & 1.411 & 1.419 & 1.405 & 1.391 & 1.398 \\
$\mathrm{O}_{7}-\mathrm{C}_{8}$ & 1.418 & 1.425 & 1.420 & 1.419 & 1.426 & 1.428 \\
$\mathrm{O}_{1}-\mathrm{C}_{2}-\mathrm{C}_{3}$ & 111.4 & 112.1 & 111.3 & 110.7 & 110.8 & 110.1 \\
$\mathrm{C}_{2}-\mathrm{C}_{3}-\mathrm{C}_{4}$ & 110.0 & 110.5 & 114.4 & 110.3 & 109.9 & 109.7 \\
$\mathrm{C}_{3}-\mathrm{C}_{4}-\mathrm{C}_{5}$ & 109.4 & 109.5 & 110.0 & 109.7 & 110.3 & 109.8 \\
$\mathrm{C}_{4}-\mathrm{C}_{5}-\mathrm{C}_{6}$ & 110.0 & 110.0 & 109.7 & 109.5 & 109.8 & 109.6 \\
$\mathrm{C}_{5}-\mathrm{C}_{6}-\mathrm{O}_{1}$ & 111.2 & 111.3 & 111.0 & 111.4 & 110.7 & 111.3. \\
$\mathrm{C}_{6}-\mathrm{O}_{1}-\mathrm{C}_{2}$ & 112.6 & 112.3 & 115.0 & 111.3 & 111.0 & 111.4 \\
$\mathrm{O}_{1}-\mathrm{C}_{2}-\mathrm{O}_{7}$ & 107.7 & 112.0 & 112.4 & 104.2 & 108.4 & 108.4 \\
$\mathrm{C}_{2}-\mathrm{O}_{7}-\mathrm{C}_{8}$ & 113.3 & 112.2 & 120.5 & 112.9 & 112.5 & 114.8 \\
$\mathrm{O}_{1}-\mathrm{C}_{2}-\mathrm{C}_{3}-\mathrm{C}_{4}$ & 56.8 & 55.3 & 46.6 & 57.4 & 57.3 & 58.5 \\
$\mathrm{C}_{2}-\mathrm{C}_{3}-\mathrm{C}_{4}-\mathrm{C}_{5}$ & 53.6 & 52.9 & 47.1 & 52.7 & 52.2 & 54.2 \\
$\mathrm{C}_{3}-\mathrm{C}_{4}-\mathrm{C}_{5}-\mathrm{C}_{6}$ & 53.6 & 53.9 & 52.0 & 52.3 & 52.1 & 52.9 \\
$\mathrm{C}_{4}-\mathrm{C}_{5}-\mathrm{C}_{6}-\mathrm{C}_{1}$ & 56.0 & 57.0 & 58.7 & 57.0 & 57.1 & 526.5 \\
$\mathrm{C}_{5}-\mathrm{C}_{6}-\mathrm{O}_{1}-\mathrm{C}_{2}$ & 59.7 & 59.5 & 60.8 & 62.4 & 63.0 & 62.0 \\
$\mathrm{C}_{6}-\mathrm{O}_{1}-\mathrm{C}_{2}-\mathrm{C}_{3}$ & 59.8 & 58.6 & 53.4 & 62.0 & 63.0 & 62.5 \\
$\mathrm{C}_{6}-\mathrm{O}_{1}-\mathrm{C}_{2}-\mathrm{O} 7$ & 62.5 & 61.7 & 78.9 & 177.2 & 177.8 & 61.7 \\
$\mathrm{C}_{4}-\mathrm{C}_{3}-\mathrm{C}_{2}-\mathrm{O} 7$ & 63.4 & 67.8 & 83.7 & 173.3 & 176.2 & 178.9 \\
$\mathrm{O}_{1}-\mathrm{C}_{2}-\mathrm{O}_{7}-\mathrm{C}_{8}$ & 159.2 & 61.1 & 99.8 & 153.0 & 62.7 & 61.7 \\
$\mathrm{C}_{3}-\mathrm{C}_{2}-\mathrm{O}_{7}-\mathrm{C}_{8}$ & 78.4 & 175.7 & 30.0 & 87.1 & 176.8 & 61.8 \\
\hline & & & & & \\
\hline
\end{tabular}

${ }^{a}$ See Scheme 1 for system numbering. 
Table 4. Geometry of lower energy conformers of 2-OMeoxane at B3LYP/6-31G(d,p) level.a (distances in $\AA$, angles in degrees)

\begin{tabular}{llllll}
\hline & $a x-1$ & $a x-2$ & $a x-3$ & $e q-2$ & $e q-3$ \\
\hline $\mathrm{O}_{1}-\mathrm{C}_{2}$ & 1.401 & 1.418 & 1.419 & 1.426 & 1.428 \\
$\mathrm{C}_{2}-\mathrm{C}_{3}$ & 1.536 & 1.530 & 1.542 & 1.525 & 1.534 \\
$\mathrm{C}_{3}-\mathrm{C}_{4}$ & 1.535 & 1.535 & 1.538 & 1.537 & 1.538 \\
$\mathrm{C}_{4}-\mathrm{C}_{5}$ & 1.536 & 1.535 & 1.533 & 1.536 & 1.535 \\
$\mathrm{C}_{5}-\mathrm{C}_{6}$ & 1.528 & 1.528 & 1.526 & 1.530 & 1.530 \\
$\mathrm{C}_{6}-\mathrm{O}_{1}$ & 1.435 & 1.435 & 1.429 & 1.424 & 1.425 \\
$\mathrm{C}_{2}-\mathrm{O}_{7}$ & 1.425 & 1.412 & 1.417 & 1.390 & 1.397 \\
$\mathrm{O}_{7}-\mathrm{C}_{8}$ & 1.412 & 1.420 & 1.417 & 1.422 & 1.424 \\
$\mathrm{O}_{1}-\mathrm{C}_{2}-\mathrm{C}_{3}$ & 111.6 & 112.1 & 112.4 & 110.8 & 110.4 \\
$\mathrm{C}_{2}-\mathrm{C}_{3}-\mathrm{C}_{4}$ & 110.8 & 111.3 & 115.0 & 110.4 & 110.1 \\
$\mathrm{C}_{3}-\mathrm{C}_{4}-\mathrm{C}_{5}$ & 109.8 & 109.8 & 109.9 & 110.6 & 110.1 \\
$\mathrm{C}_{4}-\mathrm{C}_{5}-\mathrm{C}_{6}$ & 110.0 & 110.0 & 109.6 & 110.1 & 109.9 \\
$\mathrm{C}_{5}-\mathrm{C}_{6}-\mathrm{O}_{1}$ & 111.6 & 111.8 & 112.1 & 111.2 & 111.8 \\
$\mathrm{C}_{6}-\mathrm{O}_{1}-\mathrm{C}_{2}$ & 114.3 & 113.8 & 118.1 & 112.5 & 112.9 \\
$\mathrm{O}_{1}-\mathrm{C}_{2}-\mathrm{O}_{7}$ & 108.3 & 112.3 & 113.3 & 108.6 & 108.6 \\
$\mathrm{C}_{2}-\mathrm{O}_{7}-\mathrm{C}_{8}$ & 114.6 & 113.6 & 120.7 & 114.1 & 116.4 \\
$\mathrm{O}_{1}-\mathrm{C}_{2}-\mathrm{C}_{3}-\mathrm{C}_{4}$ & 54.3 & 53.1 & 41.9 & 55.9 & 56.7 \\
$\mathrm{C}_{2}-\mathrm{C}_{3}-\mathrm{C}_{4}-\mathrm{C}_{5}$ & 52.3 & 51.8 & 47.3 & 51.4 & 53.1 \\
$\mathrm{C}_{3}-\mathrm{C}_{4}-\mathrm{C}_{5}-\mathrm{C}_{6}$ & 52.7 & 53.0 & 53.5 & 51.0 & 51.9 \\
$\mathrm{C}_{4}-\mathrm{C}_{5}-\mathrm{C}_{6}-\mathrm{C}_{1}$ & 54.9 & 55.9 & 57.1 & 55.5 & 55.0 \\
$\mathrm{C}_{5}-\mathrm{C}_{6}-\mathrm{O}_{1}-\mathrm{C}_{2}$ & 58.5 & 58.2 & 54.7 & 61.5 & 60.4 \\
$\mathrm{C}_{6}-\mathrm{O}_{1}-\mathrm{C}_{2}-\mathrm{C}_{3}$ & 57.6 & 56.4 & 45.7 & 61.6 & 60.8 \\
$\mathrm{C}_{6}-\mathrm{O}_{1}-\mathrm{C}_{2}-\mathrm{O} 7$ & 65.3 & 64.8 & 87.6 & 178.9 & 172.5 \\
$\mathrm{C}_{4}-\mathrm{C}_{3}-\mathrm{C}_{2}-\mathrm{O} 7$ & 66.9 & 70.8 & 90.3 & 175.3 & 179.9 \\
$\mathrm{C}_{1}-\mathrm{C}_{2}-\mathrm{O}_{7}-\mathrm{C}_{8}$ & 153.0 & 63.6 & 87.5 & 64.9 & 59.3 \\
$\mathrm{C}_{3}-\mathrm{C}_{2}-\mathrm{O}_{7}-\mathrm{C}_{8}$ & 83.9 & 172.6 & 44.3 & 174.4 & 64.9 \\
\hline
\end{tabular}

${ }^{a}$ See Scheme 1 for system numbering.

These results are in good agreement with those determined by calorimetric methods in gas phase by Wiberg ${ }^{14}$ and with calculations reported by Schleyer ${ }^{8}$ and Wiberg ${ }^{9}$. Our results do not contradict the idea that, as previously noted by Booth, ${ }^{12}$ an exo-anomeric interaction could be more important than an endo-anomeric interaction. Just for comparative purposes the relative energy of conformers ax-2, eq-2, ax-1, and eq-3 reported by Salzner and Schleyer are 0.0, 1.5, 4.0 , and $4.4 \mathrm{kcal} / \mathrm{mol}$, respectively. ${ }^{9}$ 
These tendencies can also be observed from the geometrical data obtained at B3LYP/6$31 \mathrm{G}(d, p)$ level (Table 4). Geometric considerations of the ab initio results point to an evident exo-anomeric effect for eq-2 and eq-3. Since the efficiency of orbital overlap is a function of the antiperiplanar alignment and in these two rotamers there are no important steric constraints, they can adapt to the geometry necessary to the stereoelectronic interactions to occur. It is not as clear for conformer ax-2, which is also undergoing an endo-anomeric interaction with opposite consequences in terms of geometry. Conformer ax-3 can be disregarded as any stereoelectronic interaction would be overwhelmed by the strong steric interactions. Conformer eq-1 is not supposed to be subject of any stereoelectronic interaction so its geometry is dictated only by steric and polar forces.

\section{Normal vibration mode analysis. Enthalpic and entropic contributions}

The calculation of the normal vibration mode at MP2 level, allows the isolation of the thermal energy, and with it, the determination of the enthalpy, the entropy, and the Gibbs free energy, at different temperatures (Table 1 of supporting information) for each conformer. Even though the calculation process for these properties can include large error, the tendencies for these results allow us to reach interesting conclusions. The $\Delta H^{\circ}$ for the most stable conformers is found between 2.02 and $0.36 \mathrm{kcal} / \mathrm{mol}$, at MP2 and B3LYP levels, respectively (without including neither the corrections of zero-level energy nor the escalating factors of the frequency values). The second value agrees with the experimental data obtained by Booth. ${ }^{12}$ The stereoelectronic contributions and the steric repulsion affect the enthalpic term in accordance with our previous analysis of energies and geometries. The stability sequence is analoguous to the one that describes the total energy, and similar to the one described at MP2 level. Table 1S shows the results obtained with the evaluation of the temperature on the relevant thermodynamic properties, calculated at MP2/6-31G(d,p).

Entropy calculated with this method only describes the degrees of vibrational freedom associated to each minimum. It is interesting to note that the conformer with less vibrational freedom is ax-2. It could be argued that keeping the most favorable stereoelectronic arrangement decreases the vibrational freedom. Conformer eq- 2 has an entropy barely higher than that of conformer ax-2, in accordance with the fact that both are subject to the same stereoelectronic exo anomeric interaction.

\section{Molecular mechanics (MM2) calculations}

Considering the populated rotameric configurations in the axial and equatorial conformers around $\mathrm{C}_{2}-\mathrm{O}_{7}$ bond rotation is fundamental from the mixing entropy's point of view. The free space intramolecular entropy ${ }^{22}$ was determined according to Juaristi et al. ${ }^{18} \Delta S^{0}$ determined at MP2 level is $0.34 \mathrm{eu}$; at B3LYP $\Delta S^{\circ}$ is only $0.20 \mathrm{eu}$, and at HF level it is $0.30 \mathrm{eu} . \Delta S^{\circ}=0.30$ with MM2 calculations. Thus the entropy of mixing in this study points to a higher entropy for the equatorial conformer, both with ab initio and with molecular mechanics. 


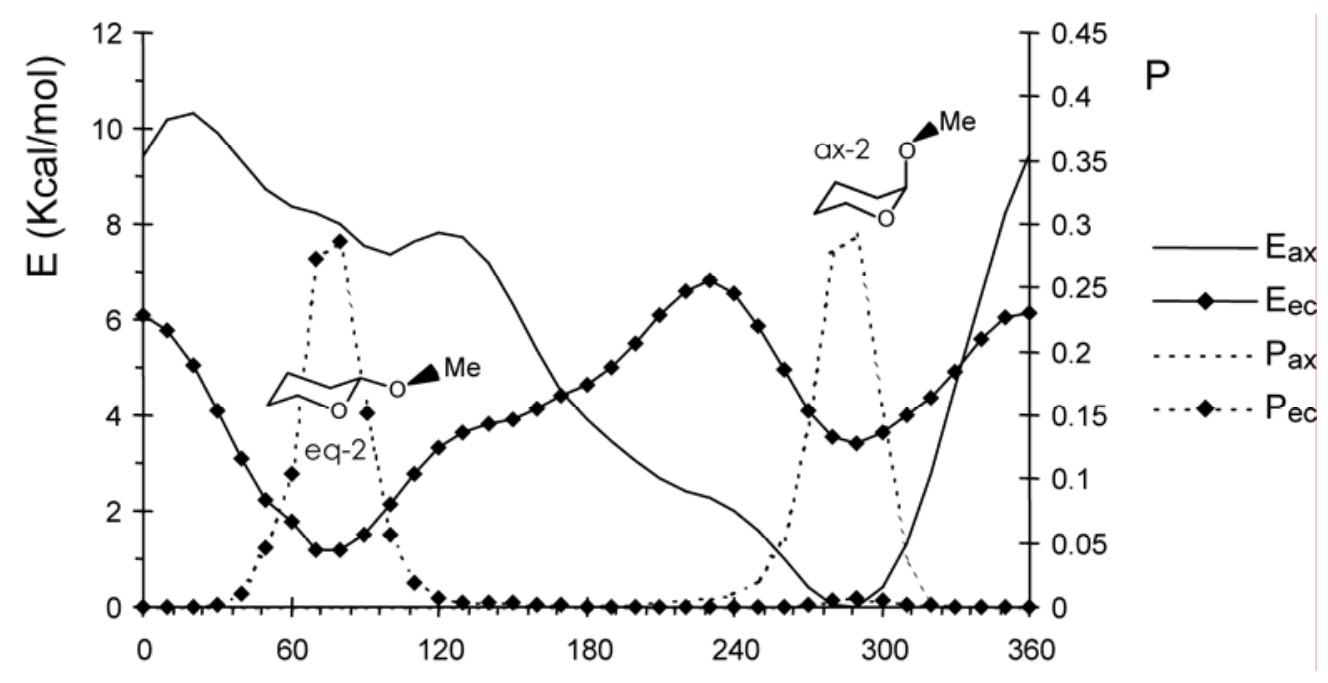

Scheme 6. Energy and population profiles for axial and equatorial 2-OMeTHP as calculated with MM2.

Molecular mechanics calculations might assist, as did calculations with the $\mathrm{E}_{\text {Lewis, }}$ in the elucidation of the forces that are acting in this system. Scheme 6 presents the energy profile of axial and equatorial 2-OMe-oxane. Energy and population profiles calculated with MM2 more or less reproduce results with ab initio and DFT methods, displaying the same patterns with respect to the energy minima relations, although the minima locations are offset by about $10^{\circ}$ and their energy barriers are about 1 to $2 \mathrm{kcal} / \mathrm{mol}$ lower.

Table 5 displays energies as calculated and analyzed with this method. Energies for conformer ax-2 are set to zeroes, as it is the global minimum. All other values are subtracted from the corresponding value of ax-2, so positive values represent values that contribute to the increase of the final steric energy, while negative values, being of less energy than their axial equivalent, have an opposite effect in the energy value.

The patterns are the same as those found in ab initio and DFT calculations. The axial conformer of minimum energy, ax-2, is $1.16 \mathrm{kcal} / \mathrm{mol}$ more stable than the minimum energy equatorial conformer, eq- 2 . In the axial profile, there is only one populated minimum. Ax-1 does not exist as a minimum energy conformer, and the high energy flattened area associated to the methoxy interaction with the ring, now looks like a broad assymetric barrier. MM2 finds the steric interactions between the methoxy and axial $\mathrm{H}_{6}$ more intense than with $\mathrm{H}_{4}$.

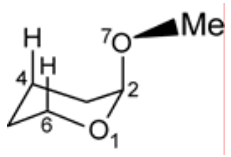

Conformer ax-2 suffers from some bending angle deformations involving $\mathrm{C}_{6}-\mathrm{O}_{1}-\mathrm{C}_{2}-\mathrm{O}_{1}-\mathrm{C}_{2}-$ $\mathrm{O}_{7}-\mathrm{C}_{8}$. Bond lengths also suffer in this moiety of the molecule. 
Table 5. MM2 Energy terms of minimun energy conformers of 2-OMeTHP

\begin{tabular}{lllllll}
\hline Energies (kcal/mol) & ax-1 & ax-2 & ax-3 & eq-1 & eq-2 & eq-3 \\
\hline Final steric energy & 3.88 & 0.00 & 7.36 & 4.65 & 1.16 & 3.41 \\
Compression & 0.08 & 0.00 & 0.05 & 0.14 & 0.05 & 0.05 \\
Bending & 0.63 & 0.00 & 4.94 & -1.48 & -1.51 & 0.02 \\
Stretch-bend & 0.050 & 0.00 & 0.18 & -0.04 & -0.08 & -0.02 \\
Vdw 1,4 & -0.01 & 0.00 & -0.02 & 0.34 & 0.52 & 0.15 \\
Vdw Other & -0.07 & 0.00 & 0.21 & -0.07 & -0.33 & 0.26 \\
Torsional & 2.34 & 0.00 & 0.57 & 4.07 & 1.50 & 2.10 \\
Dipole & 0.87 & 0.00 & 1.43 & 1.69 & 1.01 & 0.86 \\
\hline Dipole moment & 1.94 & 0.14 & 2.31 & 2.54 & 2.01 & 1.80 \\
\hline
\end{tabular}

The increased energy in ax-1 is due mainly to the torsional term (around $60 \%$ of the energy increase, Table 5); dipole energy, around 22\%; bending energy, with about $16 \%$. The carbon and oxygen backbone presents angle bending deformation and bond stretching.

The bigger contributor to the energy increase in ax-3 is the bending term, with $67 \%$ of the total increase from that of ax-2, which is not surprising since bending angles in the vicinity of $\mathrm{O}_{1}-\mathrm{C}_{2}-\mathrm{C}_{7}$ in ax-3 are deviated from their ideal values with a high energy cost. Dipolar energy also raises the energy by about $20 \%$. Interactions are more intense with $\mathrm{H}_{6}$ than with $\mathrm{H}_{4}$, due to the shorter $\mathrm{O}-\mathrm{C}$ bond lengths. Bond lengths around bond $\mathrm{O}_{1}-\mathrm{C}_{2}$ are stretched out from their ideal values too.

The energy curve of the equatorial conformer (Scheme 6) shows two energy minima, though only one is populated, eq-2. In this conformer the bending deformations along $\mathrm{C}_{6}-\mathrm{O}_{1}-\mathrm{C}_{2}-\mathrm{O}_{7}-\mathrm{C}_{8}$ are smaller, which means that in terms of bending eq- 2 is the most stable for about $1.5 \mathrm{kcal} / \mathrm{mol}$. van der Waals interactions other that 1,4 interactions also stabilize the molecule in a significant way $(0.33 \mathrm{kcal} / \mathrm{mol})$.

For rotamer eq-3 torsional energy is the principal cause of energy increase $(62 \%)$. Bending energy is bigger than for eq- 2 or ax-2, for about $1.5 \mathrm{kcal} / \mathrm{mol}$. This is expected since angles associated with $\mathrm{O}_{1}-\mathrm{C}_{2}-\mathrm{C}_{3}-\mathrm{O}_{7}-\mathrm{C}_{8}$ are more or less deviated from their ideal values. Bond lengths along all the $\mathrm{C}$ and $\mathrm{O}$ backbone are stretched, more intensely in the methoxy side of the ring, but still intense on the opposite side around C5.

Finally, eq-1 has a large torsional term that accounts for most of its final steric energy; and although the angle bending term is as low as eq-2, the dipole energy adds up to a total of 4.65 $\mathrm{kcal} / \mathrm{mol}$ above ax-2. Bending angles are not strongly deformed and bond streching is present only partially in the $\mathrm{C}$ and O-backbone. 
As an overview, angle bending energy is pretty high for ax-3 because this rotamer is very stressed due to the methoxy pointing inside the ring. The lowest angle bending values are held by eq-1 and eq-2, evidence of a relaxed geometry for these two conformers in relation to ax-2 and eq-3. Except for eq-1 and eq-2, where van der Waals 1,4 interactions are about $0.4 \mathrm{kcal} / \mathrm{mol}$ higher, the rest displays about the van der Waals same energy. Rotamers ax-3 and eq-3 display a slightly high other than 1,4 van der Waals energies.

\section{Conclusions}

The potential energy curves resulting from the $\mathrm{C}_{2}-\mathrm{O}_{\text {exo }}$ bond rotation of 2-OMeOxane were calculated. One minimum was found for the axial conformer at MP2/6-31G(d,p); B3LYP/6$31 \mathrm{G}(\mathrm{d}, \mathrm{p})$; and $\mathrm{HF} / 6-31 \mathrm{G}(\mathrm{d}, \mathrm{p})$ levels, and two minima in the equatorial conformer. The difference in the entropy of mixing between both conformers has a positive value, close to zero, which means that the entropy is higher for the equatorial conformer.

At all the levels of theory studied here, the conclusion is that the incorporation of zero point energy correction (ZPE) should lead to the observation of only one axial and two equatorial rotamers. The minimum eq-1 does not exist in contrast with the usual representation of this conformational equilibrium. The usual schemes like Scheme 2, usually described in book reviews must be changed according with the results here presented.

Finally, from the energy data obtained, it is possible to conclude that the exo-anomeric interaction is at least as relevant as the endo-anomeric, as proposed by Booth. ${ }^{13}$ The form of this potential allowed us to explain the observations made by Fuchs et al ${ }^{19}$ based on the statistic study of 111 samples containing the O-C-O-C segment. Due to the non-existence of the eq-1 conformer, and the fact that the anti-anti conformer of dimetoxymethane exists in its corresponding potential energy surface; makes this molecule inappropriate as a model to study the anomeric effect in the O-C-O segment. On the other hand, the fit between the results shown here, and the observations by Fuchs et al. ${ }^{19,20}$ allows us to settle that 2-MeOTHP is an excellent model for the study of the anomeric effect in carbohydrates.

\section{Computational Methods}

Full geometry optimization of all conformers of minimum energy studied here were performed at $\mathrm{MP} 2 / \mathrm{G}-31 \mathrm{G}(d, p)$ and B3LYP/6-31G $(d, p)$ levels with the G94 program. ${ }^{15}$ Uniform scanning at $10^{\circ}$ increments was carried out for the O-C-O-C segment determining at each point the total energy with only this dihedral angle restriction in a partial geometry optimization. Natural Bond Orbital (NBO) analysis ${ }^{16}$ was carried out with the Gaussian NBO version 3.1 included in G94. To determine the energy of the hypothetical Lewis molecule that corresponds to each rotamer, the keyword NOSTAR was used in the NBO input. ${ }^{17}$ 
The determination of the molecular entropy was done as described by Juaristi et al. ${ }^{18}$ This methodology has been useful to study the entropy of mixing contribution to the conformational free energy of several cyclohexanes and heterosubstituted cyclohexane derivatives upon the rotation of substituent groups. It must be considered that the entropy evaluated in such a way takes into account the isolated molecule, and neglects solvent interactions as well as vibrational entropy.

\section{Acknowledgements}

The authors deeply express their gratitude to CONACYT, grant 40390-Q, and DGAPA IN107597. KM and FC is grateful to CONACyT for financial support.

\section{References}

1. Lemieux, R.U. "Exploration with sugars - how sweet it was", In Profiles, Pathways and Dreams; Seeman, J.I., Ed.; American Chemical Society: Washington, D.C., 1990, and references cited there in.

2. Juaristi, E. Introduction to Stereochemistry and Conformational Analysis. Wiley; New York, 1991. Eliel, E.L.; Allinger, N.L.; Angyal, S.J.; Morrison, G.A. Conformational Analysis; Wiley: New York, 1967, p 377.

3. (a) Kirby, A.J. In The Anomeric Effect and Related Stereoelectronic Effects at Oxygen; Springer Verlag: Berlin, 1983; pp 100-102. (b) Deslongchamps, P. In Stereoelectronic Effects in Organic Chemistry; Pergamon Press: New York, 1983. (c) Szarek, W.A.; Horton, D., Eds.; Anomeric Effect: Origin and Consequences; ACS Symposium Series No. 87; American Chemical Society: Washington, D.C., 1979. (d) Juaristi, E.; Cuevas, G. Tetrahedron 1992, 48, 5019. (e) Juaristi, E.; Cuevas, G. In The Anomeric Effect. CRC Press: Boca Raton, FL, 1994. (e) Graczyk, P.P.; Mikolajczyk, M. The Anomeric Effect: Origin and Consequences In Topics in Stereochem. 1994, 21, 159.

4. (a) Wolfe, S.; Rauk, A.; Tel, L.M. Csizmadia, I.G. J. Chem. Soc. (B) 1971, 136. (b) Wolfe, S. Acc. Chem. Res. 1972, 5, 102. (c) Juaristi, E. J. Chem. Educ. 1979, 56, 438.

5. Lemieux, R.U.; Pavia, A.A.; Martin, J.C.; Watanabe, K.A. Can. J. Chem. 1969, 47, 4427.

6. (a) Booth, H.; Khedhair, K.A.; Readshaw, S.A. Tetrahedron 1987, 43, 4699. (b) Booth, H.; Readshaw, S.A. Tetrahedron 1990, 45, 2097. (c) Booth, H.; Dixon, J.M.; Readshaw, S.A. Tetrahedron 1992, 48, 6151. (d) Booth, H.; Dixon, J.M.; Readshaw, S.A. Tetrahedron 1992, 48, 6161. (e) Lemieux, R.U.; Pavia, A.A.; Martin, J.-C.; Watanabe, K.A. Can. J. Chem. 1969, 47, 4427. (f) Zefirov, N.S.; Shekhatman, N.M.; Dokl. Akad. Nauk. SSSR, 1967, 177, 842. (g) Anderson, C.B.; Sepp, D.T. Chem. Ind. (London) 1964, 2054. (h) Anderson, C.B.; Sepp. D.T. Tetrahedron 1968, 24, 1707. 
7. (a) Salzner, U.; Schleyer, P.v.R. J. Am. Chem. Soc. 1993, 115, 10231 and references cited there in. (b) Anderson, J.E. J. Org. Chem. 2000, 65, 748. (c) Eisenstein, O.; Anh, N.T.; Jean, Y.; DerAcquet, A.; Cantacuzene, S.; Salem, S. Tetrahedron 1974, 1717. (d) Allinger, N.L.; Rahman, M.; Lii, J.-H. J. Am. Chem. Soc. 1990, 112, 8293.

8. (a) Tvaroska, I.; Kozar, T. Theor. Chim. Acta 1979, 53, 9. (b) Tvaroska, I.; Kozar, T. J. Am. Chem. Soc. 1980, 102, 6929. (c) Tvaroska, I.; Kozar, T. Carbohydr, Res. 1981, 90, 173. (d) Allinger, N.L. Chung, D.Y. J. Am. Chem. Soc. 1976, 98, 6978. (e) Box, V.G.S. J. Molec. Struct. 2000, 522, 145.

9. Salzner, U.; Schleyer, P.v.R. J. Org. Chem. 1994 59, 2138.

10. Wiberg, K.B.; Murcko, M.A. J. Am. Chem. Soc. 1989, 111, 4821.

11. Cortés, F.; Tenorio, J.; Collera, O.; Cuevas, G. J. Org. Chem. 2001, 66, 2918.

12. Booth, H.; Grindley, T.B.; Khedhair, K.A. J. Chem. Soc. Chem. Commun. 1982, 1047.

13. Praly, J.-P.; Lemieux, R.U. Can. J. Chem. 1987, 65, 213.

14. Wiberg, K.B.; Marquez, M. J. Am. Chem. Soc. 1994, 116, 2197.

15. Gaussian 94, Revision D.4, Frisch, M. J.; Trucks, G.W.; Schlegel, H.B.; Gill, P.M.W.; Johnson, B.G.; Robb, M.A.; Cheeseman, J.R.; Keith, T.; Petersson, G.A.; Montgomery, J.A.; Raghavachari, K.; Al-Laham, M.A.; Zakrzewski, V.G.; Ortiz, J. V.; Foresman, J.B.; Cioslowski, J.; Stefanov, B.B.; Nanayakkara, A.; Challacombe, M.; Peng, C.Y.; Ayala, P.Y.; Chen, W.; Wong, M.W.; Andres, J.L.; Replogle, E.S.; Gomperts, R.; Martin, R.L.; Fox, D.J.; Binkley, J.S.; Defrees, D.J.; Baker, J.; Stewart, J.P.; Head-Gordon, M.; Gonzalez, C.; Pople, J.A. Gaussian, Inc., Pittsburgh, PA, 1995.

16. NBO 3.0. Glendening, E. D.; Badenhoop, J. K.; Reed, A. E.; Carpenter, J. E.; Weinhold, F. Theoretical Chemistry Institute, University of Wisconsin, Madison, WI, 1994.

17. Keyword NOSTAR: Weinhold, F.A. In Encyclopedia of Computational Chemistry; Schleyer, P.v.R., Ed.; John Wiley and Sons, Ltd. Publishers: New York, 1998; Vol 3. p 1805.

18. (a) Juaristi, E.; Labastida, V.; Antunez, S. J. Org. Chem. 2000, 65, 969. (b) Antunez, S.; Juaristi, E.; J. Org. Chem. 1996, 61, 6465. (c) Juaristi, E.; Labastida, V.; Antunez, S. J. Org. Chem. 1991, 56, 4802.

19. Fuchs, B.; Schleifer, L.; Tartakovsky, E. New J. Chem. 1984, 8, 275.

20. Schleifer, L.; Senderowitz, H. Aped, P.; Tartakovsky, E.; Fuchs, B. Carbohydr. Res. 1990, 206, 21.

21. Eliel, E.L.; Wilen, S.A. Stereochemistry of Organic Compounds; Wiley: New York, 1994. p 601.

22. Flory, P.J. Statistical Mechanics of Cain Molecules; Wiley: New York, 1969. See also: Lopez de Compadre, R.L.; Pearlstein, R.A.; Hopfinger, A.J. Seydel, J.K. J. Med. Chem. 1987, 30, 900 . 